\title{
Patient State Index Detects Changes in Cerebral Blood Flow and May Predict New Ischemic Lesions during Carotid Stenting-Case Report
}

\author{
Ana B. Fernández \\ Department of Anesthesiology, Intensive Care and Pain Treatment, Nuestra Sra De Candelaria University \\ Hospital, Santa Cruz de Tenerife, Canary Islands, Spain \\ Email: anabfp@gmail.com
}

Received 8 December 2014; accepted 16 January 2015; published 20 January 2015

Copyright (C) 2015 by author and Scientific Research Publishing Inc.

This work is licensed under the Creative Commons Attribution International License (CC BY). http://creativecommons.org/licenses/by/4.0/

c) (i) Open Access

\begin{abstract}
Carotid angioplasty and stenting (CAS) was developed to be a less invasive and complex procedure compared to carotid endarterectomy (CEA). It has emerged as an alternative for patients who are considered to have high surgical risks due to medical comorbidities or anatomical high-risk features [1]. The procedure is usually done under local anesthesia with light sedation, with the subsequent expectation of less neurologic injury, venous thromboembolisms, and myocardial infarctions-all well-known clinical risks of undergoing surgical procedures under general anesthesia. CAS, however, carries some increased risks of arterial dissection, dislocation of atherothrombotic debris and embolization to the brain or eye, late embolization due to thrombus formation on the damaged plaque, and bradycardia and hypotension as a result of carotid sinus stimulation. Electroencephalography can detect cerebral ischemia and hypoxia along with measuring hypnotic effects, but has not been reported to be used during CAS to signal impending neurological deficit and allow for intervention to prevent stroke. We report on the use of patient state index (PSI), an electroencephalographic (EEG) derived variable used by SEDLine monitor (Masimo Inc., San Diego, CA) to monitor changes in cerebral blood flow during carotid angioplasty and stenting in an awake patient under local anesthesia. PSI was developed to measure the level of hypnosis and sedation during anesthesia and in the ICU. The PSI is based on quantitative electroencephalogram features, recorded from anterior and posterior scalp sites, as input to a multivariate algorithm that quantifies the most probable level of anesthesia or sedation. The PSI is reported as a range from 0 to 100, with decreasing values indicating increasing levels of anesthesia or sedation. Adequate depth of anesthesia is reflected by PSI value of 25 - 50, and a fully awake state by a PSI of 100 [2]. Other EEG analysis techniques have been explored to detect changes in cerebral blood flow during carotid surgery [3], such as entropy described by Khan and Ozcan in his recent work entitled Disagree-
\end{abstract}


ment in Bilateral State Entropy Values in Carotid Artery Disease [4], but there are no previous reports of the use of PSI during procedural sedation in carotid angioplasty and stenting in an awake patient.

\title{
Keywords
}

\author{
Patient State Index (PSI), Carotid Angioplasty, Cerebral Ischemia, EEG Analysis
}

A 75-year-old male patient with complete occlusion of right internal carotid artery and 75\% - 93\% occlusion of left internal carotid artery, was scheduled for left internal carotid angioplasty and stenting. At the time of hospital admission, the patient presented with a transient ischemic attack within the left carotid territory and sensory-motor impairment in his right hand with an evolution of 4 to 6 hours. Clopidogrel (300 mg) was administered orally. His medical background included a history of laryngeal epidermoide cancer (T3N0M0) treated with chemotherapy and radiotherapy 11 years ago, without treatment at present, arterial hypertension controlled with a calcium antagonist and dyslipidemia, in treatment with statins.

On arrival at the Interventional Radiology Room, standard monitors and an arterial line were placed and oxygen administered at 6 - $8 \mathrm{~L} / \mathrm{min}$ by face mask. In addition, a SEDLine monitor PSI array was placed on the patient's forehead using the manufacturer instructions. The patient's initial PSI value was 98, but inter-hemispheric asymmetry was observed in the EEG waveforms of the SEDLine display. Midazolam (1 mg) was administered intravenously.

After the guide has crossed the injury and the embolic filter was deployed the PSI value fell to 27- 35 PSI, the voltage was reduced and the EEG tracing slowed predominantly in the left hemisphere, but there were no new neurological deficits or hemodynamic changes, and PSI values normalized after several minutes. A small dose of atropine $(0.5 \mathrm{mg}$ ) was administered before balloon dilatation and the stent was successfully placed into the left carotid.

The low PSI values during CAS reflected decrease in EEG activity and inter-hemispheric asymmetry, attributable to reduced cerebral perfusion and probable embolic stroke despite the embolic protection device (umbrella-type embolic filter).

Embolic filters allow particles smaller than $100 \mathrm{mc}$ to pass through, resulting in multiple small, usually asymptomatic, cerebral lesions in up to one third of patients. This type of distal micro-embolization, although not immediately associated with gross neurological deficits, could eventually lead to other problems, such as late cognitive impairment [5].

Diffusion-weighted magnetic resonance imaging performed 48 hours post-procedure, confirmed new ischemic lesions. The patient was discharged home one week later, with improved but not fully recovered sensorymotor function of the right arm, and aspirin-clopidogrel therapy.

Most recent studies have demonstrated that new embolic lesions were found twice as often after CAS than after CEA, but the decline in cognitive function was transient after CAS, whereas it persisted in patients after CEA [6] [7]. Wasser et al. observed transient cognitive decline in patients with new cerebral ischemic lesions early after CAS and CEA, and speculated that the initial decline in cognitive performance in older patients after CAS was at least partly attributable to cerebral micro-embolism. An improvement in cognitive performance during follow-up could reflect that the vast majority of new lesions after CAS are small and do not cause permanent ischemic damage [8].

Our case demonstrates that changes in PSI values during carotid angioplasty and stenting under local anaesthesia in an awake patient indicate acute changes in cerebral blood flow and may serve as a predictor of new ischemic lesions.

Finally, we found no disadvantages in the use of EEG monitors during the procedure described in our work, since it was easy to interpret and harmless to the patient. Recently, we used in clipping and brain aneurysm stent in a healthy patient, but under general anesthesia, producing acute thrombosis of the middle cerebral artery as a complication, being treated with intra-arterial and intravenous abciximab perfusion. The PSI descended slightly from 50 to 30 for a few minutes without significant changes in the EEG. The clot disappeared and the patient awoke with a normal neurological exploration. 


\section{Conflict of Interest}

None.

\section{References}

[1] Erikson, K.M. and Cole, D.J. (2010) Carotid Artery Disease: Stenting vs Endarterectomy. British Journal of Anesthesia, 105, i34-i49. http://dx.doi.org/10.1093/bja/aeq319

[2] Caputo, T., Ramsay, M., Rossmann, J., Beach, M., Griffiths, G., Meyrat, B., et al. (2011) Evaluation of the SED Line to Improve the Safety and Efficiency of Conscious Sedation. Baylor University Medical Center Proceedings, 24, 200204.

[3] Skordilis, M., Rich, N., Viloria, A., Dimitrova, G., Bergese, S. and Dzwonczyk, R. (2011) Processed Electroencephalogram Response of Patients Undergoing Carotid Endarterectomy: A Pilot Study. Annals of Vascular Surgery, 25, 909912. http://dx.doi.org/10.1016/j.avsg.2011.05.011

[4] Khan, Q.S. and Ozcan, M.S. (2011) Disagreement in Bilateral State Entropy Values in Carotid Artery Disease. Journal of Neurosurgical Anesthesiology, 23, 51-52. http://dx.doi.org/10.1097/ANA.0b013e3181f0461f

[5] Chaer, R. and Schneider, P. (2010) Carotid Stenting. Peripheral Endovascular Interventions, Part 5, 349-368. http://dx.doi.org/10.1007/978-1-4419-1387-6_24

[6] Altinbas, A., et al. (2011) Cognition after Carotid Endarterectomy or Stenting: A Randomized Comparison. Neurology, 77, 1084-1090. http://dx.doi.org/10.1212/WNL.0b013e31822e55b9

[7] Wasser, K., et al. (2011) New Brain Lesions after Carotid Revascularization Are Not Associated with Cognitive Performance. Journal of Vascular Surgery, 53, 61-70. http://dx.doi.org/10.1016/j.jvs.2010.07.061

[8] Wasser, K., et al. (2012) Age-Dependent Effects of Carotid Endarterectomy or Stenting on Cognitive Performance. Journal of Neurology, 259, 2309-2318. http://dx.doi.org/10.1007/s00415-012-6491-9 
Scientific Research Publishing (SCIRP) is one of the largest Open Access journal publishers. It is currently publishing more than 200 open access, online, peer-reviewed journals covering a wide range of academic disciplines. SCIRP serves the worldwide academic communities and contributes to the progress and application of science with its publication.

Other selected journals from SCIRP are listed as below. Submit your manuscript to us via either submit@scirp.org or Online Submission Portal.
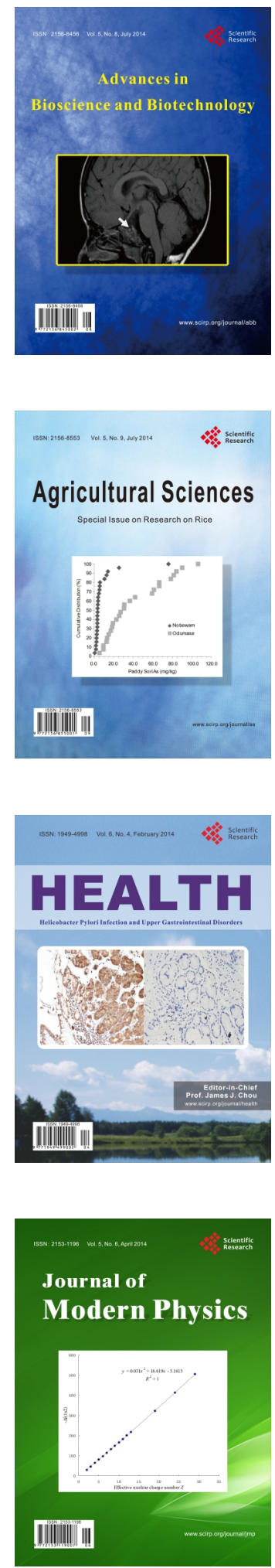
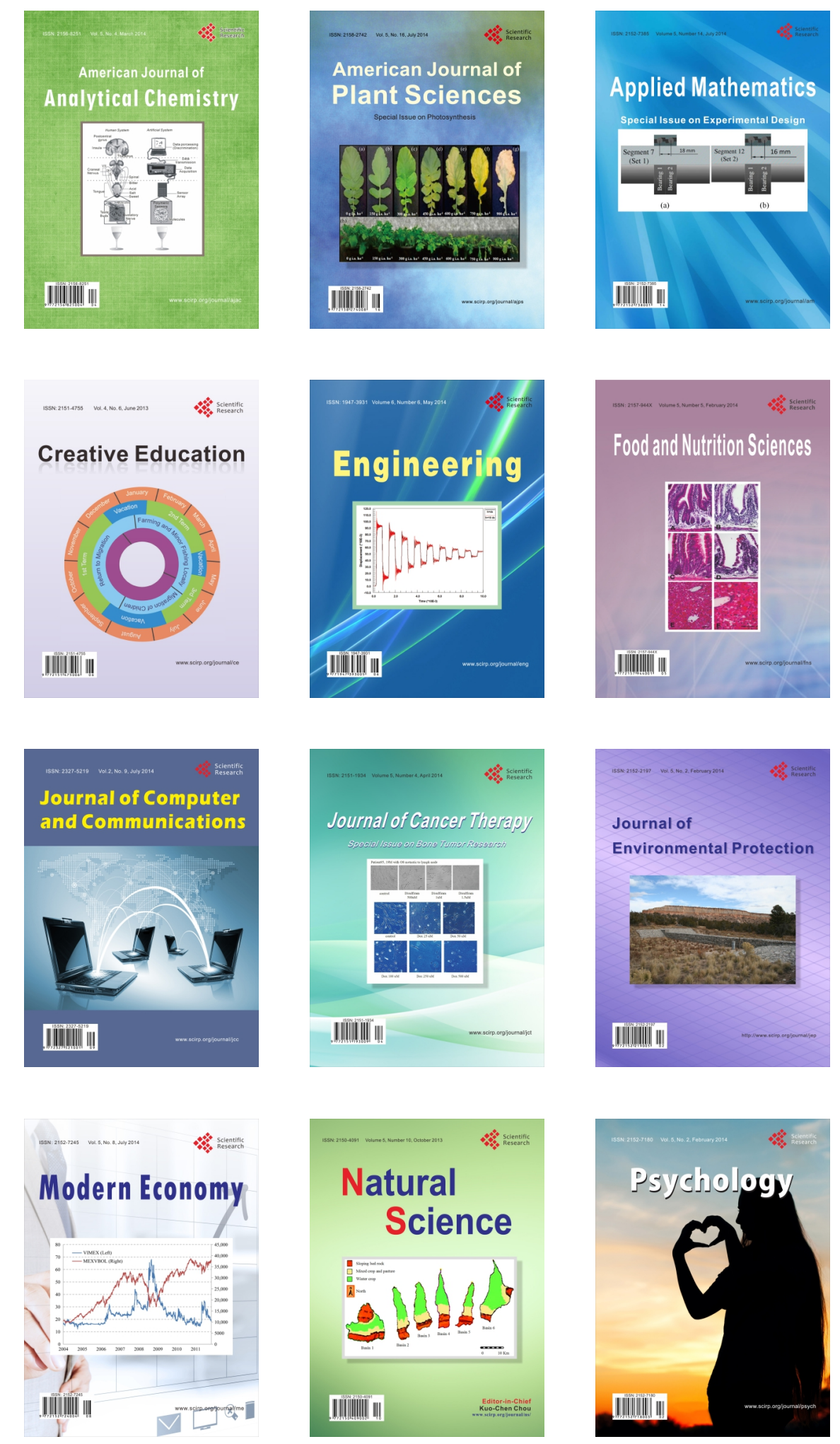